
allemande

46-2 | 2014

Intellectuels et politique en Allemagne

\title{
Catherine MAURER et Astrid STARCK-ADLER (dir.), L'espace rhénan pôle de savoirs
}

Presses universitaires de Strasbourg, 2013, 441 p.

Richard Kleinschmager

\section{(2) OpenEdition}

Journals

Édition électronique

URL : https://journals.openedition.org/allemagne/1683

DOI : 10.4000/allemagne. 1683

ISSN : 2605-7913

Éditeur

Société d'études allemandes

Édition imprimée

Date de publication : 30 décembre 2014

Pagination : 507-508

ISSN : 0035-0974

\section{Référence électronique}

Richard Kleinschmager, "Catherine MAURER et Astrid STARCK-ADLER (dir.), L'espace rhénan pôle de savoirs », Revue d'Allemagne et des pays de langue allemande [En ligne], 46-2 | 2014, mis en ligne le 29 juillet 2019, consulté le 28 mai 2021. URL : http://journals.openedition.org/allemagne/1683; DOI : https://doi.org/ 10.4000/allemagne.1683 


\section{Italiques}

Catherine MAURER et Astrid StARCK-AdLeR (dir.), avec le concours de Christiane Weeda, L'espace rhénan pôle de savoirs, Presses universitaires de Strasbourg, 2013, $441 p$.

Depuis les travaux précurseurs de la "Regional Science » de Walter Isard à la fin des années cinquante du $x x^{e}$ siècle, les économistes ont rejoint des problématiques anciennes des géographes en mettant en exergue les liens entre développement régional et aménités péri-productives. Que la production des savoirs ait un lien avec les capacités productives des territoires est au cour des recherches formalisées sur le développement économique territorial. Cette démarche fait écho aux travaux de Fernand Braudel à ceci près que si les économistes se placent sur des temps moyens, l'historien s'appuyant sur la géographie s'est calé sur le temps long pour attester de ce lien. Le projet qui est à l'origine de l'ouvrage sur "l'espace rhénan, pôle de savoirs " publié sous la direction de Catherine Maurer, professeur d'histoire à l'Université de Strasbourg, et d'Astrid Starck-Adler, germaniste, professeur à l'Université de Haute-Alsace, est sous-tendu par l'hypothèse de ce lien structurant entre développement des savoirs et développement territorial, en l'occurrence celui de cet espace axial singulier qu'a créé le Rhin. En introduction, Catherine Maurer étaie brillamment la question des dénominations de cet espace et de la métonymie qui désigne l'espace par le nom du fleuve. Elle constate que "l'espace rhénan » cède progressivement la place au "Rhin supérieur», malgré l'histoire politique controversée du terme. L'ouvrage prend le parti d'aborder la question du lien entre territoire et savoirs sur la longue durée historique, du Moyen Âge à nos jours. Ce n'est pas une des moindres originalités de cet important ouvrage de près de 450 pages, que de la traiter sous un angle pleinement transdisciplinaire et plurilinguistique, par les thématiques autant que par les auteurs.

Pas moins de vingt-quatre auteurs proposent leurs analyses, ce qui ne permet pas, malgré les efforts des éditeurs, d'éviter certaines disparités dans le ton et les niveaux d'approche. La partie consacrée aux savoirs des temps de l'humanisme, à laquelle ont contribué Georges Bischoff, Beat von Scarpatetti, James Hirstein, Jean-Marie Valentin, Astrid StarckAdler et Catherine Baud-Fouquet, fait ressortir de manière prégnante la problématique du livre, support des savoirs, et dont avec l'invention de l'imprimerie, la vallée du Rhin a été un promoteur majeur, comme l'est aujourd'hui la Californie pour la culture numérique. La contribution de Georges Bischoff illustre de manière saisissante les retombées singulières du concile de Bâle (1431-v. 1460-1480) sur le développement de l'imprimerie et audelà de nombre d'infrastructures du nœud de communication bâlois. La deuxième partie 
dénommée "savoirs pratiques, savoirs techniques », avec des contributions de Robert Mark Spaulding, Klaus-Gert Lutterbeck, Stefan Fisch, Georg Kreis, Raymond Woessner, Antoine Beyer, Maurice Blanc et Philippe Hamman, fait ressortir certaines singularités innovantes des organisations qui ont pris naissance sur l'axe rhénan supérieur, autour des réseaux techniques, des réseaux d'énergie ou de transport ou de la structuration de l'enseignement supérieur ou des organisations politiques locales et internationales. Ne peut-on pas considérer par exemple, comme le fait Robert Mark Spaulding, que dès 1805 s'amorce avec le traité de l'Octroi, matrice de commission centrale de la navigation du Rhin, l'idée d'une administration possible du territoire européen dont le siège est à Strasbourg. La troisième partie avec les contributions de Ricarda Bauschke-Hartung, Catherine T. Dunlop, Sandrine Fuss et François Wernert aborde sur une longue période les singularités et les influences confluentes dans la production culturelle. Dans cette partie aussi, la diversité des approches prime, avec des analyses de la poésie du Minnesang, des cartographies topographiques de l'Alsace du $x V l^{e}$ au $x x^{e}$ siècle, de la musique à Strasbourg durant le second conflit mondial et du renouveau liturgique au xx siècle où s'établit un lien singulier avec la Belgique. La quatrième et dernière partie de l'ouvrage est consacrée à la coexistence marquante dans cet espace des savoirs érudits et des savoirs universitaires, avec des propositions d'analyse de Marie-Renée Diot-Duriatti, Georg F. Tschan, Albert Hamm, Claude Lorentz, François Igersheim, Thomas Mohnike, Markus Enzenauer et Matthieu Funtsch. Les éléments de la culture en général et de la culture universitaire en particulier y sont présentés avec une insistance particulière sur l'originalité de certaines ouvertures vers d'autres sphères culturelles, les mondes anglo-saxon ou scandinave par exemple. Les problématiques géopolitiques du Rhin supérieur transparaissent aussi à travers l'analyse des propositions du géographe Friedrich Metz sur l'unité du Rhin supérieur ou de la Bibliographie Alsacienne et des rapports épineux qu'elle généra entre l'Université de Strasbourg et l'Institut scientifique des Alsaciens-Lorrains dans le Reich de Francfort.

L'ouvrage opère des incursions souvent éclairantes dans le domaine en perpétuelle construction des réalités interculturelles d'un espace transfrontalier, en l'occurrence l'espace rhénan supérieur. II dévoile que les développements culturels séparés par les frontières politiques ont, sur la longue durée de l'histoire, souvent été cisaillés par la réalité complexe d'échanges plus ou moins ouverts, plus ou moins discrets voire secrets. Les frontières d'État n'ont jamais aboli la possibilité de certains partages culturels même quand ils n'avaient pas officiellement droit de cité. Les idées politiques, les savoirs pratiques, techniques et scientifiques ont certainement connu dans une zone frontière comme celle du Rhin supérieur une intensité d'échange et de circulation, qui rapproche ce territoire des lieux majeurs de pouvoir et de savoir que sont les capitales d'État et leur région. Il est probable que dans le cas du Rhin supérieur la frontière a pu élever le niveau de compréhension des complexités comme elle a pu stimuler l'esprit de compétition. Dans la transformation géopolitique du continent européen, la frontière n'opère plus avec la même intensité mais elle ne saurait disparaître tant que les cultures nationales continuent de fortement nuancer géographiquement une culture commune en gestation. La réalité culturelle du Rhin supérieur s'est nourrie de la confluence compétitive des cultures nationales française, allemande et helvète. L'ouvrage étaie l'hypothèse que les cultures dans l'espace rhénan supérieur et partant les sociétés, tant au plan économique et social que politique, se sont nourries de ces apports. Dans le contexte de l'intégration européenne, cette confluence peut désormais s'opérer pacifiquement et librement. Ces nouvelles opportunités de circulation maintiendront-elles les exigences qui se sont souvent manifestées dans les temps anciens de la compétition? C'est l'une des questions d'avenir qui se posent dans l'espace rhénan pôle de savoirs. 